\title{
Uroflowmetry in a Large Population of Brazilian Men Submitted to a health check up program and its correlation with ipss and prostate size
}

João Paulo Zambon, Nelson Sivonei da Silva Batezini, Amir Jamil Karam Junior, Raquel Dilguerian Oliveira Conceição, José Antônio Maluf de Carvalho, Fernando G. Almeida

Hospital Israelita Albert Einstein (JPZ, NSSB, AJKJ, RDOC, JAMC), Universidade Federal de São Paulo (JPZ, NSSB, FGA), São Paulo, SP, Brazil and Wake Forest University (JPZ), NC, USA

\section{ABSTRACT}

Purpose: The aim of this study was to assess the uroflowmetry data in a large population of asymptomatic Brazilian men submitted to a health check up program and their correlation to IPSS and prostate size.

Materials and Methods: Asymptomatic men underwent a health check-up program between January and December 2012. The inclusion criteria were men between 40 and 70 years, IPSS $\leq 7$, without bladder, prostate, urethral surgery, neurological diseases, urinary tract infection, PSA $<4.0 \mathrm{ng} / \mathrm{dL}$ and urinary volume higher than $150 \mathrm{~mL}$. Urological assessment consisted of clinical history, IPSS, digital rectal examination (DRE), prostate specific antigen (PSA), urinalysis, ultrasonography and uroflowmetry.

Results: A total of 1041 asymptomatic men were included in this study. The average age was 49 years and average maximum flow rate was $17.4 \mathrm{~mL} / \mathrm{s}$. In spite of IPSS and prostate size increase with aging, they had a weak correlation with $Q_{\max }$ cutoffs $(10 \mathrm{~mL} / \mathrm{s}$ and $15 \mathrm{~mL} / \mathrm{s})$. A total of 85 men (8.3\%) had more than 60 years, and even in this group, $\mathrm{Q}_{\max }$ was higher than $15 \mathrm{~mL} / \mathrm{s}$. Out of 1041 men, 117 had IPSS less than 8 and $\mathrm{Q}_{\max }$ less than $10 \mathrm{~mL} / \mathrm{s}$.

Conclusions: In asymptomatic men there is a weak correlation between IPSS, prostate size and uroflowmetric data. The establishment of different normal cutoffs seems to be complicated and uroflowmetry data should be interpreted with caution in order to avoid misdiagnosis.

\section{ARTICLE INFO}

\section{Key words:}

Asymptomatic Diseases;

Prostate; Prostatic Hyperplasia;

Urinary Bladder

Int Braz J Urol. 2013; 39: 841-6

Submitted for publication:

June 11, 2013

Accepted after revision:

August 12, 2013

\section{INTRODUCTION}

Most men have a progressive prostate enlargement after fourth decade. The main consequence of benign prostate hyperplasia (BPH) is bladder outlet obstruction (BOO), which is characterized by high bladder pressure and low flow rates. The natural history of $\mathrm{BPH}$ is not well es- tablished and the long-term consequence of B00 remains unclear $(1,2)$.

The assessment of prostatic symptoms usually is performed with the International Prostate Symptom Score (IPSS). Regarding prostate symptoms, asymptomatic men are those with IPSS less than 8. Routinely, uroflowmetry is not indicated in this specific population. 
Uroflowmetry is a non-invasive method that may help the urologist to diagnose bladder outlet obstruction. However, it is not able to distinguish BOO and detrusor underactivity (DUA). Both bladder dysfunctions can be characterized by low maximum flow rate $\left(Q_{\max }\right)(1,2)$.

Likewise men with B00, asymptomatic men also may have low urinary maximum flow rate. For this reason, $Q_{\max }$ in men with or without symptoms should be interpreted with caution. There is a lack of studies in the literature in this specific population (3).

The aim of this study was to assess the uroflowmetry data in a large population of asymptomatic Brazilian men submitted to a health check up program and their correlation it with IPSS and prostate size.

\section{MATERIALS E METHODS}

Local Ethical Committee approved the study and all subjects filled out a written informed consent. This study was performed in asymptomatic men submitted to a health check-up program between January and December 2012. A multidisciplinary team composed by general clinicians, urologists, ophthalmologists, dermatologists, nutritionists and physiotherapists, evaluated patients. Urological assessment consisted of clinical history, IPSS, digital rectal examination (DRE), prostate specific antigen (PSA), urinalysis, ultrasonography and uroflowmetry.

The inclusion criteria were men between 40 and 70 years, IPSS $\leq 7$, without bladder, prostate, urethral surgery, neurological diseases, urinary tract infection, PSA $<4.0 \mathrm{ng} / \mathrm{dL}$ and urinary volume higher than $150 \mathrm{~mL}$.

Uroflowmetry and ultrasonography for post-void residual urine measurement (PVR) were performed during the urological evaluation. PSA and urinalysis were collected on the same day and before starting the check up.

Data was analyzed using Statistical $\mathrm{Pa}-$ ckage for Social Sciences (SPSS) version 8.0 for Windows. Pearson's linear correlation coefficient was calculated to estimate the correlation between numeric variables and multiple linear regressions to investigate the association between uroflowmetry parameters, clinical and ultrasound data. The Pearson's Chi-Square was performed to compare numeric variables. It was considered statistically significant $p$ values $\leq 0.05$.

\section{RESULTS}

Out of 2880 men, 1041 asymptomatic men with mean age of $49 \pm 6.9$ years old (range 40 to 70) were included in this study. Demographics, IPSS, prostate size and uroflowmetry data can be seen on Table- 1 .

Men were categorized into three different aging groups ( 40 to 50, 51 to 60 and 61 to 70). The older men had higher IPSS, prostate size, flow time and micturition time than younger men $(p=0.001, p=0.001, p=0.001$ and $p$ $=0.001$ respectively). On the other hand $Q_{\max }$ and $Q_{\text {med }}$ were higher in younger men. Hesitation time, PVR and maximum flow time were not statistic significant $(\mathrm{p}=0.31, \mathrm{p}=0.31$ and $\mathrm{p}=0.11$ respectively). Prostate size, IPSS, post-void residual urine and uroflowmetry data in the three groups can be observed on Table- 2 .

A second analysis was performed comparing the men with $Q_{\max }>15 \mathrm{~mL} / \mathrm{s}$ and $Q_{\max }<$ $15 \mathrm{~mL} / \mathrm{s}$. A total of 424 men (40.7\%) with average age 50.9 years had $\mathrm{Q}_{\max }<15 \mathrm{~mL} / \mathrm{s}$, whereas 617 men (60.3\%) with average age 48.8 years had $Q_{\max }>15 \mathrm{~mL} / \mathrm{s}$. The $Q_{\max }$ cutoff $15 \mathrm{~mL} / \mathrm{s} \mathrm{had}$ a weak correlation with aging, IPSS and prostate size on asymptomatic men. These data can be observed on Table-3.

A further analysis was performed in order to correlate the clinical data with lower $Q_{\max }$ cutoff $(<10 \mathrm{~mL} / \mathrm{s})$. A total of 117 men $(11.2 \%)$ had $Q_{\max }$ less than $10 \mathrm{~mL} / \mathrm{s}$ and IPSS less than 8 . The average age of this specific population was 55.5 years old. Older men had higher IPSS and prostate size, however the average $Q_{\max }$ and $Q_{\text {med }}$ were not correlated with aging when we considered only men with $Q_{\max }$ less than $10 \mathrm{~mL} / \mathrm{s}$. These data can be observed on Table- 4 .

\section{DISCUSSION}

To our knowledge, this study is the first one to assess uroflow, IPSS and prostate size in a 
Table 1 - Demographics and uroflowmetry data of 1041 men submitted to a health check up program.

\begin{tabular}{lcc}
\hline & Mean \pm sd & Median (range) \\
\hline Age (years) & $49 \pm 6.9$ & $49(40-70)$ \\
IPSS & $1.9 \pm 0.8$ & $1.5(1-7)$ \\
Prostate Size $(\mathrm{g})$ & $26.6 \pm 9.0$ & $25(10-90)$ \\
Voided Volume $(\mathrm{mL})$ & $370 \pm 161$ & $302(300-500)$ \\
Post-void residual Urine $(\mathrm{mL})$ & $14 \pm 10$ & $6(0-187)$ \\
Hesitation time $(\mathrm{s})$ & $9.2 \pm 5.9$ & $8(3-60)$ \\
Flow time $(\mathrm{s})$ & $34.5 \pm 17.8$ & $31(9-73)$ \\
Total voided time $(\mathrm{mL})$ & $44.3 \pm 34.6$ & $40(20-153)$ \\
Maximum flow time $(\mathrm{s})$ & $11.3 \pm 7.4$ & $10(5-21)$ \\
$Q_{\max }(\mathrm{mL} / \mathrm{s})$ & $17.4 \pm 7.4$ & $16.3(8-39)$ \\
$Q_{\operatorname{med}}(\mathrm{mL} / \mathrm{s})$ & $11.9 \pm 3.3$ & $10.2(7-23)$ \\
\hline
\end{tabular}

IPSS = International Prostate Symptom Score; $\mathbf{Q}_{\max }=$ maximum flow rate; $\mathbf{Q}_{\text {med }}$ : average flow rate; $\mathbf{s d}=$ standard deviation

Table 2 - IPSS, prostate size and uroflow data on three different aging groups.

\begin{tabular}{lcccc}
\hline & $40-50$ years & $50-60$ years & $60-70$ years & $p$ \\
\hline Subjects & $620(59.5 \%)$ & $336(32.2 \%)$ & $85(8.3 \%)$ & \\
IPSS & $1.0 \pm 0.5$ & $2.5 \pm 1$ & $5.7 \pm 3$ & 0.001 \\
Prostate size (grams) & $23 \pm 6.4$ & $29 \pm 9.5$ & $35 \pm 14$ & 0.001 \\
Voided volume (mL) & $347 \pm 150$ & $335 \pm 140$ & $304 \pm 165$ & 0.01 \\
Post-void residual urine (mL) & $11.5 \pm 9$ & $19.1 \pm 7$ & $15.6 \pm 5$ & 0.31 \\
Hesitation time (s) & $9.2 \pm 6$ & $9.1 \pm 5.4$ & $9.6 \pm 5.8$ & 0.31 \\
Flow time (mL/s) & $32.8 \pm 16$ & $36.5 \pm 17$ & $40 \pm 20$ & 0.001 \\
Micturition time (s) & $43.1 \pm 20$ & $45.6 \pm 19$ & $49.8 \pm 24$ & 0.001 \\
Maximum flow time (s) & $11.1 \pm 7$ & $11.8 \pm 7$ & $11 \pm 9$ & 0.11 \\
$Q_{\max }(\mathrm{mL} / \mathrm{s})$ & $18.3 \pm 7$ & $16.4 \pm 6.3$ & $15 \pm 7.7$ & 0.001 \\
$Q_{\operatorname{med}}(\mathrm{mL} / \mathrm{s})$ & $13.4 \pm 5.2$ & $10.1 \pm 5$ & $8.8 \pm 4$ & 0.001 \\
\hline
\end{tabular}

IPSS = International Prostate Symptom Score; $\mathbf{a}_{\max }=$ maximum flow rate; $\mathbf{a}_{\text {med }}=$ average flow rate 
Table 3 - IPSS, Prostate size and uroflow data on men with $Q_{\max }>15 \mathrm{~mL} / \mathrm{s}$ and $Q_{\max }<15 \mathrm{~mL} / \mathrm{s}$.

\begin{tabular}{|c|c|c|c|c|}
\hline & $Q_{\max }<15 \mathrm{~mL} / \mathrm{s}$ & $Q_{\max }>15 \mathrm{~mL} / \mathrm{s}$ & Pearson & $p$ \\
\hline Subjects & $424(40.7 \%)$ & $617(60.3 \%)$ & & \\
\hline Age (years) & $50.9 \pm 7.6$ & $48.8 \pm 6.3$ & -0.161 & 0.01 \\
\hline IPSS & $3 \pm 1$ & $1 \pm 0.5$ & -0.256 & 0.001 \\
\hline Prostate size $(\mathrm{g})$ & $28.3 \pm 11$ & $25.4 \pm 7.9$ & -0.166 & 0.001 \\
\hline Voided volume (mL) & $256 \pm 127$ & $396 \pm 177$ & 0.133 & 0.001 \\
\hline PVR (mL) & $17 \pm 7$ & $12 \pm 5$ & -0.132 & 0.001 \\
\hline Hesitation time(s) & $10.5 \pm 7.2$ & $8.3 \pm 4.7$ & -0.214 & 0.003 \\
\hline Flow time(s) & $40.2 \pm 21$ & $30.6 \pm 13.9$ & -0.267 & 0.001 \\
\hline Micturition time(s) & $50.2 \pm 23$ & $40.3 \pm 20$ & $-0,149$ & 0.001 \\
\hline Maximum flow time(s) & $13.3 \pm 9.3$ & $10 \pm 5$ & -0.234 & 0.001 \\
\hline Average $Q_{\text {med }}(\mathrm{mL} / \mathrm{s})$ & $6.7 \pm 2$ & $15 \pm 7$ & 0.130 & 0.001 \\
\hline Average $Q_{\text {max }}(\mathrm{mL} / \mathrm{s})$ & $11.42 \pm 2.8$ & $21.47 \pm 4.1$ & 0.290 & 0.001 \\
\hline
\end{tabular}

IPSS = International Prostate Symptom Score; $\mathbf{a}_{\max }=$ maximum flow rate; $\mathbf{a}_{\operatorname{med}}=$ average flow rate.

Table 4 - IPSS, prostate size and uroflow data on men with $a_{\max }<10 \mathrm{~mL} / \mathrm{s}$.

\begin{tabular}{lcccc}
\hline & $40-50$ years & $50-60$ years & $60-70$ years & $p$ \\
\hline Subjects & $42(35.8 \%)$ & $57(48.7 \%)$ & $18(15.3 \%)$ & \\
IPSS & $1.7 \pm 1.5$ & $4.7 \pm 3.2$ & $6.4 \pm 3.19$ & 0.001 \\
Prostate size (grams) & $22.9 \pm 8.8$ & $32.6 \pm 9.2$ & $39.8 \pm 9.2$ & 0.001 \\
Voided volume (mL) & $180.7 \pm 170$ & $229 \pm 172$ & $201 \pm 173$ & 0.06 \\
Post-void residual urine $(\mathrm{mL})$ & $8.9 \pm 22$ & $26.01 \pm 22.4$ & $17.4 \pm 22$ & 0.05 \\
Hesitation time $(\mathrm{s})$ & $15.5 \pm 6.07$ & $11.7 \pm 5.8$ & $12.1 \pm 5.72$ & 0.07 \\
Flow time $(\mathrm{mL} / \mathrm{s})$ & $38.8 \pm 17.9$ & $49.9 \pm 17.8$ & $50.8 \pm 17.8$ & 0.05 \\
Micturition time $(\mathrm{s})$ & $51.9 \pm 35.40$ & $62.5 \pm 34.6$ & $63 \pm 34.8$ & 0.05 \\
Maximum flow time $(\mathrm{s})$ & $14.5 \pm 7.48$ & $17.8 \pm 7.5$ & $11.5 \pm 7.54$ & 0.06 \\
Average $Q_{\text {max }}(\mathrm{mL} / \mathrm{s})$ & $8.37 \pm 1.23$ & $8.60 \pm 1.15$ & $8.57 \pm 0.89$ & 0.43 \\
Average $Q_{\text {med }}(\mathrm{mL} / \mathrm{s})$ & $4.71 \pm 1.27$ & $4.85 \pm 3.90$ & $4.42 \pm 3.5$ & 0.41 \\
\hline
\end{tabular}

IPSS = International Prostate Symptom Score; $\mathbf{a}_{\max }=$ maximum flow rate; $\mathbf{a}_{\text {med }}=$ average flow rate. 
very specific population of Brazilian asymptomatic men submitted to a health check-up program. The IPSS and prostate size increased with aging however they had a weak correlation with different $Q_{\max }$ cutoffs ( $10 \mathrm{~mL} / \mathrm{s}$ and $15 \mathrm{~mL} / \mathrm{s}$ ). The average age of men was 49 years and their average maximum flow rate was $17.4 \mathrm{~mL} / \mathrm{s}$. A total of 85 men (8.3\%) had more than 60 years, and even in this group, $Q_{\max }$ was higher than $15 \mathrm{~mL} / \mathrm{s}$. Out of 1041 men, 117 had IPSS less than 8 and $Q_{\max }$ less than $10 \mathrm{~mL} / \mathrm{s}$.

The urinary flow is a result of the interaction between detrusor contraction and urethral resistance. Low urinary flow may suggest B00 or bladder underactivity. Abnormal findings in uroflowmetric parameters can suggest voiding dysfunction but the uroflowmetry by itself has a low specificity and does not allow the confirmation of the etiologic diagnosis. Since there is not a clear correlation between symptoms and pressure flow studies, an objective parameter is desirable in order to improve the BOO diagnosis. The main issue in missing B00 is the potential to develop bladder deterioration due to non-treated high urethral resistance $(3,4)$.

The normal value is better determined by studying a large number of patients in order to evaluate the variable distribution. There is a lack of studies describing the uroflowmetry parameters in a large population. Many flow-volume nomograms have been constructed. Siroky nomogram was based on data of 300 voids of 80 asymptomatic men and validated it plotting results of 33 normal men and 53 men with obstructive voiding symptoms. Liverpool nomogram was based on a large number of observations and underwent preliminary validation using 30 observations of one normal volunteer $(5,6)$.

It is not a consensus among urologists to perform uroflow and pressure flow studies in the routine assessment of men with lower urinary tract symptoms. The definition of normality can be based on Gaussian or mean \pm standard deviation; percentile within a specified range such as 5\% to 95\%; culturally desirable; risk factor or an individual with no additional risk of disease; diagnostic or a range of results beyond which target disorder are highly probable and therapeutic or a range of results beyond which treatment does more good than harm $(4,7)$. We have seen a high range of variability in uroflowmetric parameters in asymptomatic subjects. Based on our findings, we believe that the establishment of normal values in uroflowmetric parameters in male population seems to be complicated.

Some authors suggested different maximum flow-rate cut-off values in order to distinguish men with or without bladder outlet obstruction. Higher cut-off maximum flow rates decrease the specificity and increase the sensitivity. On the other hand lower cut-off maximum flow rates increase the specificity and decrease the sensitivity. According to Reynard et al., when $Q_{\max }$ was less than $10 \mathrm{~mL} / \mathrm{s}$, the test specificity and sensitivity were respectively $70 \%$ and $47 \%$. Likewise, when $\mathrm{Q}_{\max }$ was lower than $15 \mathrm{~mL} / \mathrm{s}$, the test specificity and sensitivity were respectively $38 \%$ and $82 \%$ $(8,9)$. In this study 117 men with IPSS less than 8 had $Q_{\max }$ less than $10 \mathrm{~mL} / \mathrm{s}$, which suggest no correlation between $Q_{\text {max }}$ and urinary symptoms. For this reason, uroflow data should be interpreted with caution.

Although symptoms usually stimulate patients to seek treatment, some studies have shown that there is no correlation between symptoms and bladder outlet obstruction $(10,11)$. Uroflowmetry can be an additional tool for urologists before surgical intervention or treatment failure. Abrams et al. demonstrated that $90 \%$ of men with maximum flow rate lower than $10 \mathrm{~mL} / \mathrm{s}$ have some degree of obstruction. Conversely, 25\% to 30\% of men with decreased flow rate are not obstructed (12).

Urodynamic studies are the most definitive tests available to determine the etiology of voiding dysfunction and lower urinary tract symptoms. The filling and storage phase can provide useful information such as involuntary contractions, bladder sensation, bladder capacity and impaired compliance. Currently, urologists have been used pressure-flow nomograms to demonstrate B00, however they are essentially based on symptomatic patients with low urinary tract symptoms due to benign prostatic hyperplasia. Walker et al. studied the pressure-flow data in 24 asymptomatic men with mean age 61 years. The peak flow rate and detrusor pressure at maximum 
peak flow were respectively $17.9 \pm 17.5 \mathrm{~mL} / \mathrm{s}$ and $49.5 \pm 26.2 \mathrm{~cm} \mathrm{H}_{2} \mathrm{O}$. On pressure flow studies 3 patients had unequivocal obstruction, 7 were in the equivocal area and 14 had no obstruction. These findings suggest that even asymptomatic men can be obstructed (7).

There are a few data on literature regarding the voiding characteristics of "normal" men. Specifically in the developing countries such as Brazil, the data registration is inadequate and in most cases we have used American or European population data as a reference. In this context, this study provides a substantial data of a specific Brazilian men population. In spite of our findings, the primary aim of this study was not to establish normal uroflowmetric values or create uroflow nomograms. We have thought that uroflow is an additional tool to evaluate voiding dysfunction and should be interpreted linked with clinical and ultrasonographic data in order to avoid misdiagnosis.

\section{CONFLICT OF INTEREST}

None declared.

\section{REFERENCES}

1. Al-Hayek S, Thomas A, Abrams P: Natural history of detrusor contractility--minimum ten-year urodynamic follow-up in men with bladder outlet obstruction and those with detrusor. Scand J Urol Nephrol Suppl. 2004; 215: 101-8.

2. Thomas AW, Cannon A, Bartlett E, Ellis-Jones J, Abrams $P$ : The natural history of lower urinary tract dysfunction in men: minimum 10-year urodynamic follow-up of untreated detrusorunderactivity. BJU Int. 2005; 96: 1295-300.

3. Rosario DJ, Woo HH, Chapple CR: Definition of normality of pressure-flow parameters based on observations in asymptomatic men. Neurourol Urodyn. 2008; 27: 388-94.
4. Nitti VW: Pressure flow urodynamic studies: the gold standard for diagnosing bladder outlet obstruction. Rev Urol. 2005; 7 Suppl 6: S14-21.

5. Siroky MB, Olsson CA, Krane RJ: The flow rate nomogram: II. Clinical correlation. J Urol. 1980; 123: 208-10.

6. Haylen BT, Ashby D, Sutherst JR, Frazer MI, West CR: Maximum and average urine flow rates in normal male and female populations--the Liverpool nomograms. $\mathrm{Br} \mathrm{J}$ Urol. 1989; 64: 30-8.

7. Walker RM, Romano G, Davies AH, Theodorou NA, Springall RG, Carter SS: Pressure flow study data in a group of asymptomatic male control patients 45 years old or older. J Urol. 2001; 165: 683-7.

8. Reynard JM, Yang Q, Donovan JL, Peters TJ, Schafer W, de la Rosette JJ, et al.: The ICS-'BPH' Study: uroflowmetry, lower urinary tract symptoms and bladder outlet obstruction. Br J Urol. 1998; 82: 619-23.

9. de la Rosette JJ, Witjes WP, Schäfer W, Abrams P, Donovan JL, Peters TJ, et al.: Relationships between lower urinary tract symptoms and bladder outlet obstruction: results from the ICS-"BPH" study. Neurourol Urodyn. 1998; 17: 99-108.

10. McLoughlin J, Gill KP, Abel PD, Williams G: Symptoms versus flow rates versus urodynamics in the selection of patients for prostatectomy. Br J Urol. 1990; 66: 303-5.

11. Gerstenberg TC, Andersen JT, Klarskov P, Ramirez D, Hald T: High flow infravesical obstruction in men: symptomatology, urodynamics and the results of surgery. J Urol. 1982; 127: $943-5$.

12. Abrams P, Bruskewitz R, de La Rossette J: The diagnosis of bladder outlet obstruction: urodynamics. In: Cockett ATK, Khouri S, Aso Y, et al., eds. Proceedings, the 3rd Consultation on BPH. World Health Organization. 1995; 299-367.

Correspondence address:
João Paulo Zambon, MD, PhD
Female Urology and Voiding Dysfunction Department
Federal University of Sao Paulo
UNIFESP-EPM
Research at Wake Forest Institute
for Regenerative Medicine
E-mail: jp-zambon@uol.com.br

João Paulo Zambon, MD, $\mathrm{PhD}$ oiding Dysfunction Departmen UNIFESP-EPM E-mail:.jp-zambon@uol.com.br 